\title{
Darwin e os darwinistas
}

\author{
Lilian Al-Chueyr Pereira Martins
}

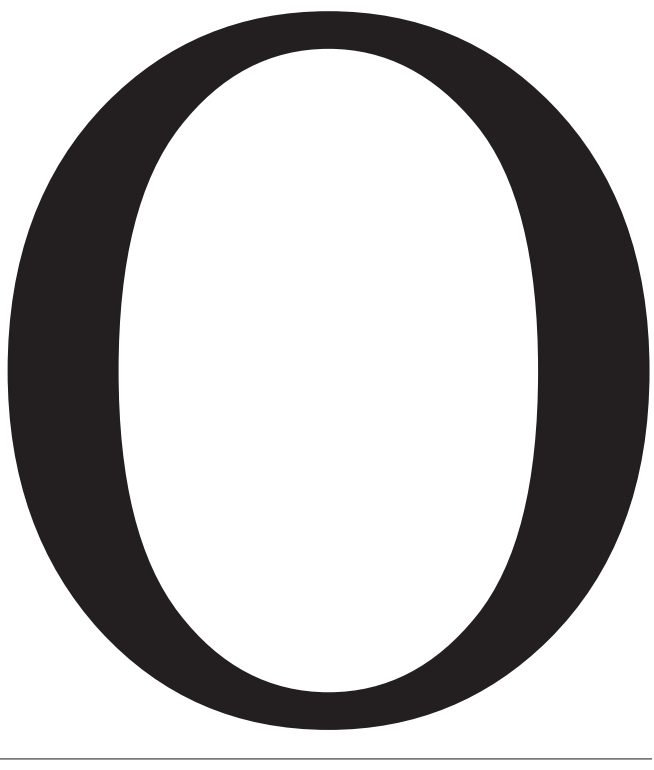

ano de 2019 é significativo para a história da biologia, particularmente, para a história da evolução, pois nele se comemoram os 210 anos do nascimento de Charles Robert Darwin (1809-1882) e os 160 anos da publicação do livro Origin of species (Origem

A autora agradece ao Conselho Nacional de Desenvolvimento Científico e Tecnológico (CNPq) e à Fundação de Amparo à Pesquisa do Estado de São Paulo (Fapesp) pelo apoio concedido, sem o qual não seria possível a realização desta pesquisa.

\section{LILIAN AL-CHUEYR PEREIRA MARTINS é} professora do Departamento de Biologia da Faculdade de Filosofia, Ciências e Letras de Ribeirão Preto e pesquisadora do Grupo de História e Teoria da Biologia, ambos da USP. 
das espécies, 1859). Essa obra, que teve seis edições, mudou completamente o estudo da biologia. Assim, aproveitamos a oportunidade para revisitar a proposta original de Darwin e seu contexto, mas também para discutir um pouco sobre o que ocorreu depois.

Ao defender a teoria da descendência com modificação, em substituição à ideia de que as espécies eram fixas, Darwin se opôs à visão que era aceita pela maioria dos naturalistas de sua época ${ }^{1}$. Entretanto, como nos mostra a própria história da ciência, a aceitação de uma nova teoria não é algo imediato e simples e, nesse sentido, Darwin contou com a ajuda de colaboradores que apoiaram e defenderam sua teoria perante a comunidade científica ${ }^{2}$.

O círculo de Darwin era constituído por diversos estudiosos, tais como Thomas Henry Huxley (1825-1895), Charles Lyell (17971875), Herbert Spencer (1820-1903), Joseph Dalton Hooker (1817-1911), Alfred Russel Wallace (1823-1913) e George John Romanes (1848-1894), dentre outros. Enquanto Darwin era vivo, eles apoiavam suas ideias e as eventuais divergências ficavam restritas a discussões no âmbito privado. Porém, após a morte de Darwin, os membros de seu cír-

1 Na época em que Darwin desenvolveu seus estudos e, posteriormente, quando publicou sua teoria, os administradores e a maioria dos professores da Universidade de Cambridge eram anglicanos. Eles condenavam a evolução, já que admitiam a criação e a fixidez das espécies. Apesar de estar submetida ao governo, a Igreja Anglicana controlava o sistema educacional do país (Desmond \& Moore, 1995, p. 53; Bizzo, 1989, p. 56; Carmo, 2006, p. 8)

2 O próprio Darwin estava consciente disso, como se pode perceber em uma carta que escreveu para Thomas Huxley, um dos principais defensores de sua teoria: "Se pudermos construir um conjunto unido de crentes, venceremos no futuro" (Carta de Darwin para Huxley, 27/11/1989, in Francis Darwin, 1887, volume 2, apud R. Martins, 2006, p. 211). culo se envolveram em discussões de caráter público, enfatizando em suas publicações as diferenças em seu modo de pensar, disputando a posição de liderança em relação aos estudos sobre evolução, antes ocupada por Darwin. Assim, Spencer, Romanes e Wallace, cada um por si e em assuntos diferentes, envolveram-se em controvérsias com August Friedrich Leopold Weismann (1834-1914), que acreditava que a seleção natural explicava tudo no processo evolutivo (Martins, 2008, p. 288).

Durante boa parte do tempo foi Thomas Huxley, conhecido como o bulldog de Darwin, quem defendeu sua teoria publicamente. Entretanto, nos últimos anos de vida de Darwin, este papel coube a George John Romanes (Martins, 2006, p. 219).

\section{A FORMAÇÃO DE DARWIN}

Darwin nasceu em uma abastada família inglesa. Aos 16 anos, seu pai o encaminhou para estudar medicina na Escócia, na Universidade de Edinburgh. Enquanto permaneceu nessa cidade, Darwin participou ativamente das reuniões em uma sociedade de história natural, a Plinian Society. Além disso, frequentou aulas teóricas e práticas de geologia, tendo como professor Robert Jameson (17741854). Entretanto, em relação ao curso de medicina propriamente dito, que não chegou a concluir, sua experiência foi desastrosa. As aulas não o motivavam e ele passava muito mal ao presenciar procedimentos cirúrgicos. Foi então encaminhado para Cambridge para se preparar para a carreira eclesiástica, que também não seguiu. Lá estudou botânica, entomologia, química, mineralogia e geologia (Desmond \& Moore, 1995; Darwin, 1958). 
Após graduar-se em 1831, Darwin fez uma excursão geológica ao norte do País de Gales, com seu professor de mineralogia, Adam Sedgwick (1785-1873). No mesmo ano, outro de seus professores de Cambridge, o naturalista John Stevens Henslow (1796-1861), responsável pela cadeira de botânica, recebeu um convite para acompanhar o capitão Fitzroy, na condição de naturalista de bordo no navio HMS Beagle. Henslow declinou o convite e indicou Darwin para substituí-lo. Após vencer a resistência de seu pai, em fins de dezembro de 1831, Darwin partiu para uma viagem ao redor do mundo (Mayr, 1982, p. 397). Durante essa viagem, ele escreveu um diário (Darwin, 1933) ${ }^{3}$ e depois de retornar, em 1837, começou a registrar seus estudos e reflexões em quatro cadernos de anotações que são designados Notebooks A, $B, C$ e $D$. Esses cadernos contêm elementos importantes que possibilitam compreender o processo de elaboração de sua teoria da transmutação das espécies.

\section{A VIAGEM DO BEAGLE}

Ao iniciar a viagem do Beagle, que durou cinco anos, de modo análogo a seus professores Sedgwick e Henslow e à maioria dos naturalistas da época, Darwin acreditava que as espécies eram fixas. Durante toda a viagem, foi coletando espécimes de plantas e animais, que iam sendo enviados para Henslow. Em 29 de fevereiro de 1832, o Beagle chegou ao Brasil, aportando em

3 Embora o diário de Darwin tenha sido escrito durante sua viagem a bordo do Beagle, ele só foi publicado posteriormente (em 1933), editado por Norma Barlow.
Salvador (Bahia). Nessa ocasião Darwin pôde visualizar algo inteiramente novo para ele: a floresta tropical. Durante maio, junho e julho do mesmo ano, ele esteve nas proximidades do Rio de Janeiro. Entretanto, ao contrário de Fitzroy, ficou chocado com a escravidão. Em julho de 1832, o Beagle navegou para Montevidéu. Darwin viajou pelos pampas, onde teve a oportunidade de fazer observações geológicas. Lá ele encontrou uma nova espécie de avestruz e também ossos fósseis de espécies que pareciam ter sido extintas em um passado geológico recente. Depois disso, o Beagle visitou a Terra do Fogo e as Ilhas Falkland, onde Darwin pôde investigar animais marinhos mais simples, como os corais. Durante esse período, teve a oportunidade de ler os dois volumes dos Principles of geology (Princípios de geologia), de Charles Lyell (1797-1875), e de fazer considerações sobre algumas formações geológicas como a Cordilheira dos Andes, por exemplo, que ele considerou ter se formado durante o Período Terciário através da ação de terremotos (Bowler, 1996, pp. 53-61).

Em setembro de 1835, o Beagle chegou ao arquipélago de Galápagos, um grupo de ilhas de origem vulcânica situadas no Pacífico, que atualmente pertencem ao Equador. Darwin se interessou particularmente pela fauna local: as tartarugas e os tentilhões ${ }^{4}$ característicos das diferentes ilhas. As tartarugas diferiam pelo formato de seus cascos e os tentilhões, pelo formato de seus bicos, além de outras características. Poste-

4 Existe atualmente uma discussão entre os biólogos no que se refere aos tentilhões. Questiona-se se os pássaros encontrados por Darwin (finches) eram tentilhões. Entretanto, estamos nos referindo a eles como a maioria da literatura especializada o faz. 
riormente, dentre os tentilhões que haviam sido enviados por Darwin para a Inglaterra durante sua viagem no Beagle, o ornitologista John Gould (1804-1881) reconheceu 30 espécies diferentes, divididas em quatro grupos. Ele constatou que os diferentes formatos de bicos exibidos por essas aves eram adaptados ao modo de alimentação. Darwin considerou a hipótese de que esses pássaros tivessem se originado de uma espécie derivada de um ancestral da América do Sul que havia se modificado e diversificado nas ilhas isoladas (Bowler, 1996, pp. 61-3). Entretanto, segundo Peter Bowler, as anotações feitas por Darwin em seu diário indicam que ele demorou bastante para perceber o significado das diferenças encontradas entre as populações das diferentes ilhas, ao contrário do que muitas vezes se pensa. Darwin chegou a comentar, inclusive, que a princípio não havia prestado atenção ao comentário do vice-governador de $\mathrm{Ga}$ lápagos, o sr. Lawson, de que ele, assim como os habitantes das diversas ilhas que constituíam o arquipélago, podia identificar a tartaruga pertencente a cada uma delas através de sua aparência (Darwin, 1891; Bowler, 1996, pp. 64 e 287). Após deixar Galápagos, o Beagle rumou para o Taiti e Nova Zelândia, Ilhas Maurício, Santa Helena e novamente para a Bahia. A seguir, navegou através do Atlântico, chegando à Inglaterra em 2 de outubro de 1836.

\section{A CONSTRUÇÃO DA TEORIA DE DARWIN}

Após retornar de sua viagem, já tendo abandonado a ideia de que as espécies eram fixas e em busca de uma explicação em relação a seu mecanismo de modificação, Darwin começou a fazer suas primeiras anotações, que registrou no Notebook $A$ (Gould, 1977, p. 21).

De acordo com alguns historiadores da ciência, como Peter Bowler, Robert Young e Ernst Mayr, a leitura do Essay on the principle of population (Ensaio sobre o princípio da população), de Thomas R. Malthus, durante a viagem do Beagle trouxe elementos que contribuíram para a elaboração do princípio da seleção natural de Darwin, em relação à luta pela existência e preservação das variações favoráveis em animais e plantas. No notebook de 1838, Darwin fez alusão a essa obra (Bowler, 1989, p. 164; Young, 1992, p. 120; Mayr, 1982, p. 478; Darwin, 1958, p. 120; Carmo, 2006, p. 19). Entretanto, isso não significa que sem a leitura da obra de Malthus Darwin não teria conseguido elaborar sua teoria, como explicam autores como Anna Carolina Regner (2008), por exemplo.

Em fins de janeiro de 1839, Darwin casou-se com sua prima Emma Wedgwood, cujo pai era proprietário da fábrica das famosas porcelanas Wedgwood. Inicialmente o casal se instalou em Londres, entretanto, após o casamento, Darwin começou a apresentar problemas de saúde. Ele sentia náuseas, perturbações intestinais e palpitações. Devido a esses sintomas, ficou impossibilitado de ter uma vida normal, incluindo contatos acadêmicos mais inten$\operatorname{sos}^{5}$. Mais tarde Darwin e sua família se mudaram para a Down House, localizada

5 Há autores que consideram que Darwin teria contraído a doença de Chagas durante a viagem no Beagle. Outros atribuem esses sintomas a problemas de ordem psicológica. 

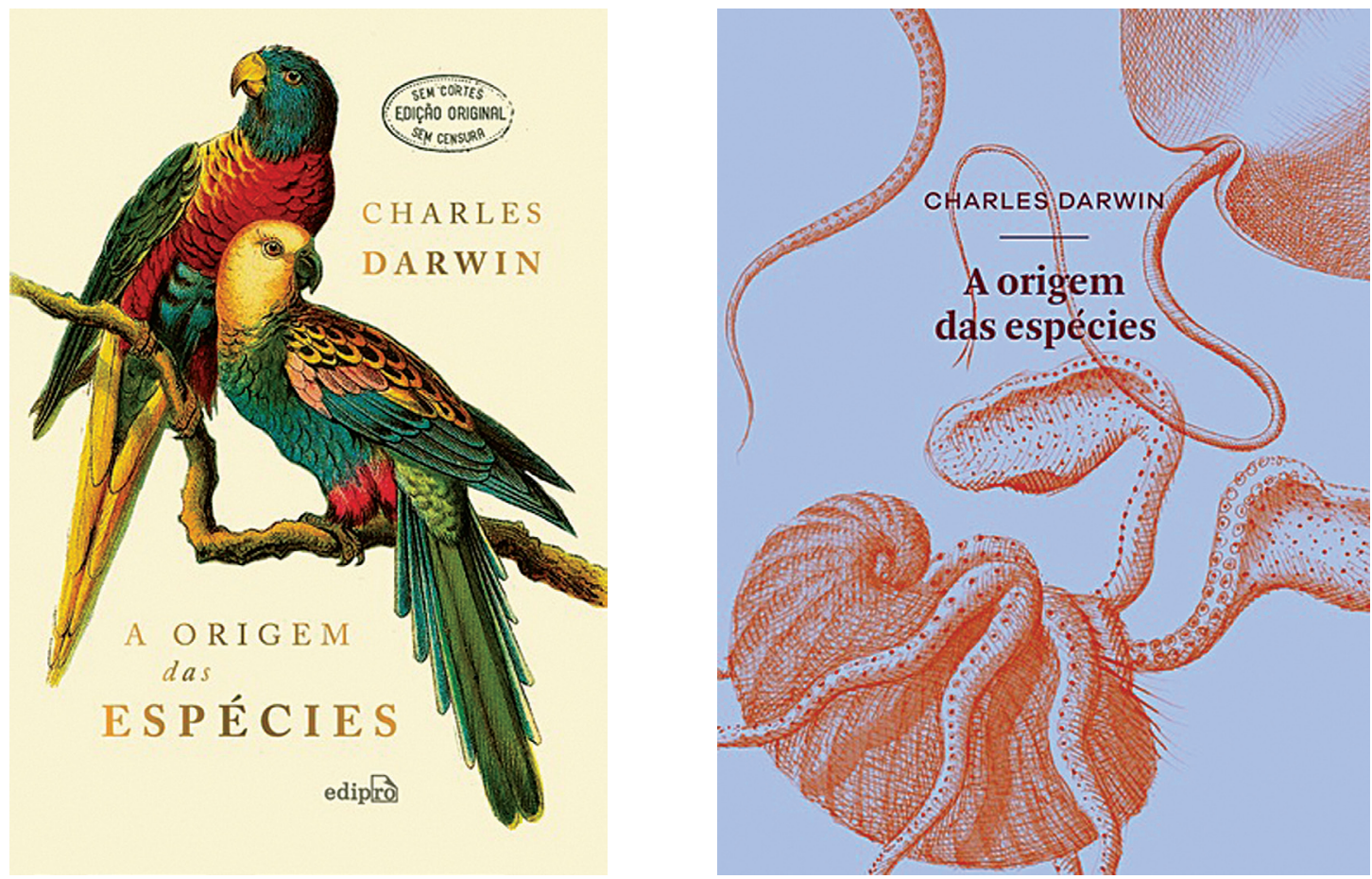

Capas de duas recentes edições de A origem das espécies. Da Editora Edipro (à esquerda), com tradução de Daniel Moreira Miranda, e (à direita) da Ubu Editora, com tradução de Pedro Paulo Pimenta

em Kent, a duas horas de Londres (Beer, 1981, p. 566).

Após ter redigido o primeiro notebook, Darwin redigiu os outros três nos quais esclareceu alguns aspectos de sua teoria, cuja primeira versão concluiu em 1842. Continuou trabalhando nos 16 anos seguintes, acumulando uma grande quantidade de informações obtidas através de intensa correspondência com criadores, agricultores e naturalistas (Bowler, 1996, p. 89). É provável que todo esse cuidado estivesse relacionado às críticas que haviam sido dirigidas às outras obras publicadas anteriormente sobre evolução, dentre as quais se incluíam as de Lamarck, a Zoonomia de seu avô, o médico Erasmus Darwin, e a de Robert Chambers (Carmo, 2006, p. 20).

Alguns dos amigos mais próximos de Darwin, como Hooker e Lyell, por exemplo, tinham conhecimento do trabalho que ele estava desenvolvendo. Em torno de 1856 eles o encorajaram a tornar públicas suas ideias. Entretanto, Darwin não seguiu o conselho dos amigos. No verão de 1858 recebeu uma carta acompanhada de um manuscrito de Alfred Russel Wallace, um jovem naturalista que havia visitado o Arquipélago Malaio. Nesse manuscrito Wallace apresentava ideias semelhantes às de Darwin em relação ao princípio da seleção natural. Nessa ocasião, Lyell e Asa Gray propuseram uma apresentação conjunta dos artigos de Darwin e Wallace em uma reunião na Linnean Society de Londres, o que se concretizou. Em seguida, os dois trabalhos foram publicados no periódico daquela sociedade. $\mathrm{O}$ fato de Wallace ter chegado independentemente à concepção do princípio da seleção natural apressou a 
publicação de Origin of species em 1859, já que a intenção inicial de Darwin era publicar uma versão bem mais longa de sua teoria, que deveria estar concluída em 1860 (Bowler, 1996, p. 108).

\section{OS PRINCIPAIS PRESSUPOSTOS DA TEORIA ORIGINAL DE DARWIN}

A proposta original de Darwin se caracterizou pela apresentação de uma grande quantidade de evidências de que a evolução é um fato; pela busca de explicações para as causas da evolução orgânica; e do papel dessas causas em casos particulares. Além disso, Darwin tentou responder a objeções às suas ideias e indicou linhas de pesquisa promissoras.

A partir do artigo publicado em 1858 e no Origin of species, em 1859, Darwin propôs a teoria da descendência com modificação de acordo com a qual as espécies viventes (incluindo os seres humanos) não surgiram como se apresentam hoje em dia: descendem de espécies extintas e ancestrais comuns modificadas por causas naturais. Uma dessas causas é a seleção natural, que foi considerada por ele como o principal, mas não exclusivo, meio de modificação das espécies. A seleção natural é um processo semelhante à seleção artificial, empregada consciente ou inconscientemente pelo criador de animais ou pelo criador de plantas ornamentais para produzir novas variedades. A seu ver, o processo evolutivo é lento e gradual. A seleção natural age sobre variações leves que ocorrem ao acaso dentro de uma população, preservando aquilo que for útil para os organismos. Essas variações são transmitidas aos descendentes. Como nasce um número maior de indivíduos do que poderiam sobreviver, existe uma luta pela existência. Nessa luta sobrevivem os indivíduos mais aptos, que deixam descendentes. Além da seleção natural, Darwin atribuiu outras causas naturais para a transformação das espécies, como a seleção sexual que explicava a beleza de algumas características apresentadas pelo macho de algumas espécies que influenciam sua escolha pela fêmea e consequente produção de descendentes, e a herança de caracteres adquiridos pelo uso e desuso. Embora admitisse a existência de variações bruscas (que chamou de sports), Darwin não as considerou relevantes para o processo evolutivo. Além disso, em uma obra que publicou posteriormente, propôs a hipótese da pangênese ${ }^{6}$, na qual procurava explicar os diversos tipos de herança, mas principalmente a herança de caracteres adquiridos pelo uso e desuso (Martins, 2006, pp. 263-4).

No parágrafo acima apontamos alguns dos principais pressupostos da teoria original de Darwin. Entretanto, ele não apresentou uma proposta fechada, já que na introdução da sexta edição de Origin of species sugeriu várias linhas de investigação que poderiam ser exploradas futuramente e trazer esclarecimentos sobre a origem das espécies, tais como: o estudo de animais domesticados e plantas cultivadas, as afinidades mútuas

6 Darwin considerava que todas as partes ou órgãos dos organismos animais e vegetais expeliam gêmulas que eram partículas submicroscópicas e portadoras das características das células, tecidos e órgãos. As gêmulas se reuniam nos gametas. Algumas delas se manifestavam nos indivíduos e outras não, ficando dormentes. Entretanto, essas últimas eram passadas para os descendentes das gerações futuras, podendo vir a se manifestar. Isso explicaria a reversão ou atavismo, fenômeno que era estudado na época (Martins, 2006, pp. 213-4). 
entre os seres orgânicos, as relações embriológicas, a distribuição geográfica e a sucessão geológica (Darwin, 1972, p. 2; Martins, 2006, p. 264).

Como mencionamos na introdução deste artigo, Darwin reuniu um grupo em torno de si com o qual interagia. Esse grupo defendia a sua teoria. Será que essas pessoas que se consideravam seguidoras de Darwin e se diziam darwinistas, ou que muitas vezes eram rotuladas de darwinistas, adotavam todos os pressupostos da teoria original de Darwin?

\section{CÍRCULO DE DARWIN}

Um dos principais defensores da teoria de Darwin no âmbito público foi Thomas Huxley. Apesar disso, ele considerava que se Darwin tivesse atribuído uma importância maior para as variações bruscas, sua teoria teria ficado bem mais consistente. Além disso, fazia várias restrições à hipótese da pangênese.

Wallace, alguns anos após a morte de Darwin, em sua obra Darwinism (1899)7 continuou aceitando vários aspectos da teoria original de Darwin, como a luta pela existência, a sobrevivência do mais apto, a preservação das variações úteis dos organismos pela seleção natural, o princípio da divergência de caracteres, a importância da variabilidade existente entre os indivíduos de uma mesma espécie e sua transmissão aos descendentes, a analogia entre o que a seleção natural fazia na natureza e o que o criador de animais e o

7 Utilizamos a segunda edição dessa obra, datada de 1890. agricultor faziam através da seleção artificial. Porém, manifestou também algumas discordâncias. Por exemplo, ao contrário de Darwin, ele acreditava que a seleção natural não explicava a origem da natureza moral e das faculdades mentais do homem. Segundo Wallace, os rudimentos da maioria das faculdades morais e mentais do homem não podem ser detectados nos animais, como pensava Darwin. A favor de sua posição, Wallace argumentava que nos "selvagens inferiores" a maioria das faculdades morais e mentais do homem é pouco desenvolvida em comparação às raças civilizadas. A seu ver, para explicar a origem das faculdades mentais do homem, é preciso recorrer a "alguma outra influência, lei ou agente" (Wallace, 1890, p. 465). Além disso, tinha uma ideia diferente da de Darwin acerca da origem e significado da diferenciação sexual em relação à estrutura, cor e ornamentação dos machos. A seu ver, essas características não dependem da escolha ou preferência da fêmea, mas estão relacionadas à proteção ou reconhecimento pelo próprio tipo e resultam da ação da seleção natural. Em pássaros e lagartos, por exemplo, essas características permitem ao animal não só esconder-se do inimigo como da própria presa. Assim, para ele a seleção sexual se restringiria ao combate entre os machos pela posse da fêmea. Negava a herança de caracteres adquiridos pelo uso e desuso, considerando "a seleção natural como o único fator invariável e sempre presente na mudança orgânica" (Wallace, 1890, p. 444; Carmo, 2006, pp. 71-5).

Outro ardoroso defensor da teoria de Darwin, enquanto ele estava vivo, foi George John Romanes. Quando iniciou sua 
colaboração com Darwin, Romanes tinha 26 anos e Darwin, 65. Romanes foi encarregado por Darwin de defender a hipótese da pangênese (Castañeda, 1992; Polizello, 2009, cap. 2) e buscar evidências que a fundamentassem $^{8}$ (Martins, R. 2006, p. 212; Polizello, 2009, cap. 2). Em 1871 essa hipótese tinha recebido críticas por parte de Francis Galton (1822-1911), meio primo de Darwin (Galton, 1871, p. 393).

Partindo do pressuposto de que as gêmulas circulavam no corpo e eram transmitidas aos descendentes e que, portanto, deveriam estar presentes no sangue, Galton fez uma série de experimentos envolvendo cruzamentos com coelhos de variedades diferentes consideradas puras da raça Silvergrey, que haviam sofrido transfusões, para averiguar se a prole apresentava ou não sinais de mistura. Os resultados obtidos foram negativos (Polizello, 2009, pp. 25-31).

De acordo com Roberto de A. Martins, Romanes, após ter dedicado vários anos ao teste da hipótese da pangênese, não conseguiu encontrar resultados que a corroborassem. Além disso, suas investigações não resultaram em nenhuma publicação. Ele procurou complementar a teoria de Darwin com novos conceitos e hipóteses. Estudou a continuidade da inteligência das formas inferiores até o homem, buscando uma explicação natural para o surgimento das diversas faculdades. Como vimos anteriormente, Wallace negava que as faculdades mentais no homem pudessem ter surgido através da seleção natural. Após a morte de Darwin, Romanes publicou vários livros sobre o assunto 9 . Porém, chegou à conclusão de que a evolução mental era produzida principalmente pela atividade social, que levava ao desenvolvimento da linguagem (Bowler, 1989, p. 236; Martins, 2006, p. 218) e não através da seleção natural, como pensava Darwin.

\section{MAIS RADICAL DOS NEO-DARWINISTAS}

Weismann defendeu a relevância do princípio da seleção natural em uma época em que este estava sendo bastante criticado. Ele formulou sua teoria de evolução principalmente na década de 1890 , porém ela foi divulgada somente no início do século XX (1902-1904) $)^{10}$.

Como Darwin, Weismann acreditava que a evolução ocorre em um processo lento e gradual através de variações contínuas e que o principal agente das mudanças evolutivas é a seleção natural. Porém, ele foi mais radical que Darwin ao admitir que "toda a parte essencial de uma espécie não é meramente regulada pela seleção, mas produzida originalmente por ela" (Weismann, 1904, vol. 2, p. 312). Além disso, acreditava que a adaptação é um efeito da seleção natural. Após a morte de Darwin, Weismann passou a fazer críticas à herança de caracteres adquiridos, acabando por rejeitá-la, enquanto Darwin a aceitou até o fim de sua vida.

9 Animal intelligence (1882), Mental evolution in animals (1883) e Mental evolution in man (1888).

10 Inicialmente em alemão e depois em inglês, numa versão revista pelo próprio Weismann. 
Em sua teoria evolutiva, Weismann propôs a existência da seleção em diversos níveis ${ }^{11}$, que incluíam o individual (seleção pessoal e seleção sexual), em unidades vivas menores que o indivíduo (estruturas celulares microscópicas e submicroscópicas) e em unidades vivas maiores que o indivíduo, as colônias (Martins, 2000, p. 279).

A teoria de evolução de Weismann está intimamente relacionada à sua teoria sobre a estrutura do plasma germinativo ${ }^{12}$, que foi proposta a partir de 1892. De acordo com essa teoria, só é transmitido aos descendentes o que for modificado no plasma dos gametas. Assim, não há herança de caracteres adquiridos porque as modificações que ocorrem nas células somáticas não são passadas para os descendentes.

Ao admitir que "toda parte essencial de uma espécie não era apenas regulada

11 Para Weismann, a seleção pessoal (seleção natural e seleção sexual) acontecia entre indivíduos. A seleção histonal (luta entre tecidos ou partes dos tecidos nos organismos pluricelulares ou entre os bióforos nos organismos mais simples) e a seleção germinal (entre os bióforos e determinantes nos indivíduos pluricelulares) ocorriam em unidades menores que os indivíduos; e a seleção cormal, luta entre colônias (de pólipos, formigas, cupins), como um todo, ocorria em unidades maiores que o indivíduo (Martins, 2000, p. 282).

12 De acordo com Weismann, o plasma dos gametas é constituído por diversas estruturas. Algumas delas podem ser vistas ao microscópio e outras não. As estruturas mais simples, que ele denominou "bióforos" e "determinantes", não seriam visíveis ao microscópio. Já os "ids" e "idantes" seriam visíveis ao microscópio. Os bióforos seriam, segundo Weismann, as menores unidades vitais que constituíam os tecidos. Os determinantes seriam constituídos por grupos inseparáveis de bióforos, responsáveis pelas características de cada órgão ou tecido. Corresponderiam aos fatores mendelianos da época. Os ids seriam constituídos por um conjunto de determinantes associados a todos os tecidos e partes dos organismos. As células germinativas conteriam os ids provenientes de diversos ancestrais. Os ids correspondiam aos microssomos da época; os idantes, que correspondiam aos cromossomos, seriam constituídos por vários ids (Martins, 2006). pela seleção natural, mas produzida originalmente por ela", Weismann foi mais radical que Darwin, o qual, na sexta edição de Origin of species, havia afirmado: "Eu estou convencido de que a seleção natural é o principal mas não exclusivo meio de modificação" (Darwin, 1872, p. 421).

\section{ALGUMAS CONSIDERAÇÕES}

Como foi possível perceber através deste breve relato, Darwin não apresentou uma proposta fechada no Origin of species, mas inaugurou um programa de pesquisa aberto a novas contribuições. Nem os próprios membros do círculo de Darwin seguiam todos os pressupostos de sua teoria. Eles adotaram alguns dos aspectos da teoria de Darwin, rejeitaram outros e, muitas vezes, acrescentaram novos aspectos.

É exatamente isso o que ocorre com algumas teorias. Conforme o tempo vai passando, alguns aspectos vão sendo esclarecidos e novas evidências são encontradas, o que faz com que sejam introduzidas modificações, como foi o caso da teoria de Darwin, que por essa razão pode ser caracterizada como um programa de pesquisa. Wallace e Weismann, por exemplo, não aceitavam a herança de caracteres adquiridos pelo uso e desuso na fase madura de sua obra. Há outros casos na história da ciência em que a teoria é substituída como um todo, como, por exemplo, o caso da física aristotélica, que foi substituída pela física newtoniana. Nesse segundo caso, trata-se de paradigmas diferentes.

Se os próprios seguidores de Darwin, que se diziam darwinistas, não adotaram a teoria de Darwin como um todo, o que 
se pode pensar em relação à síntese evolutiva $^{13}$ e seus desdobramentos ${ }^{14}$, nos séculos $\mathrm{XX}$ e XXI, com todas as suas nuances, tão distantes em termos cronológicos da proposta de Darwin? Entre elas ocorreu o desenvolvimento da genética clássica, da genética das populações (um instrumental importante para o estudioso da evolução), da biologia molecular, a partir da proposta do modelo de DNA, como resultado de um trabalho coletivo.

Atualmente a seleção natural é considerada dentro de um quadro hierárquico.

13 A síntese evolutiva ou síntese moderna é descrita por Ernst Mayr como um movimento que ocorreu entre 1936 e 1947 caracterizado pela convergência de diversas disciplinas e o consenso entre os biólogos evolutivos em relação a alguns aspectos: o gradualismo do processo evolutivo, a ideia de que as espécies são agregados populacionais, o efeito dos fatores ecológicos e o abandono do princípio da herança de caracteres adquiridos. Ela resultou dos desenvolvimentos da genética, da teoria da seleção natural (modelos matemáticos e experimentais do estudo de evolução); da aplicação de métodos experimentais quantitativos ao estudo da biologia; da fusão da nova genética com a teoria da seleção natural e da necessidade de isolamento geográfico na fase inicial de especiação (Mayr, 1982, p. 567). Além desses componentes, devem ser consideradas a mutação, a recombinação em populações com reprodução sexual e a deriva genética (Reif, Junker \& Hoßfeld, 2000, pp. 58-9). Alguns autores, como Betty Smocovittis (1996), consideram que o período da síntese foi até a década de 1960; outros, como Aldo Araújo (2006), questionam se houve de fato uma síntese ou constrição, já que algumas disciplinas, como a embriologia, foram deixadas de lado (Santos, 2015, p. 23).

14 A partir da década de 1980 foram encontradas evidências de que nem toda variação herdável resulta de diferenças no DNA e nem toda variação ocorre ao acaso, por exemplo (Jablonka \& Lamb, 2008, pp. 242-3). Além disso, alguns autores consideram que se passou a trabalhar dentro de uma perspectiva diferente da adotada pela síntese evolutiva, a síntese estendida, que inclui epigenética, plasticidade fenotípica, evo-devo (Janblonka \& Lamb, 2008, pp. 250-1; Pigliucci \& Muller, 2010, cap. 1), aspectos que não foram considerados pela síntese. Essa nova abordagem foi formalizada em 2008, porém, nem todos concordam que se esteja diante de uma extensão da síntese (Santos, 2015, pp. 30-1).
Portanto, se aplica a diferentes níveis do mundo biológico. Entretanto, acredita-se que as variações, em sua grande maioria, não são nem úteis, nem injuriosas, mas neutras. Uma grande quantidade de variação genética surge nas populações naturais através de processos aleatórios de mutação (nos genes e cromossomos) e através da recombinação. Por outro lado, sabe-se que nem sempre a evolução é gradual, como pensava Darwin. Não se aceita a herança de caracteres adquiridos pelo uso e desuso, um importante pressuposto da teoria original de Darwin adotado até o fim de sua vida, bem como sua hipótese para explicar a hereditariedade (a pangênese).

Entretanto, como o próprio Darwin pensava, admite-se hoje em dia que a seleção natural não explica tudo.

Será que o fato de não se aceitar boa parte da teoria original de Darwin atualmente torna sua contribuição menos significativa? A resposta é negativa. Em primeiro lugar, deve-se considerar uma proposta científica dentro de seu contexto. Em segundo lugar, é possível enumerar uma série de desdobramentos relevantes que mostram a significância da proposta de Darwin. Um deles é ter permitido um novo enfoque sobre o estudo dos seres vivos. Por exemplo, o estudo da classificação dos seres vivos (sistemática) passou a ser feito de outra forma, levando em conta sua origem e relações com outras espécies. Outro exemplo seriam os estudos ecológicos, que levam em conta as relações entre os indivíduos de uma mesma espécie, entre espécies diferentes e com o meio. Os próprios estudos que se seguiram à contribuição de Darwin e que consideraram populações e não indivíduos isolados não deixam de ter se inspirado na contribuição 
de Darwin. Na medicina, os estudos de fisiologia que levam em conta as relações que existem entre os diferentes órgãos são fortemente influenciados pelas ideias darwinianas de correlação entre órgãos e funções. Se a ciência atual considera que a evolução é um fato, Darwin contribuiu significativamente para que isso acontecesse.

\section{BIBLIOGRAFIA}

ARAÚJO, Aldo Mellender. "Estará em curso o desenvolvimento de um novo paradigma teórico para a evolução biológica?", in Lilian Al-Chueyr Pereira Martins; Anna Carolina Krebs Pereira Regner; Pablo Lorenzano (eds.). Ciências da vida: estudos históricos e filosóficos. Campinas, AFHIC, 2006, pp. 1-27.

BEER, Gavin de. "Darwin, Charles", in Charlton Coulston Gllispie (ed.). Dictionary of scientific biography, vol. 3. New York, Charles Scribner's Sons, 1981, pp. 566-76.

BIZZO, Nélio Vincenzo. Darwin. Do telhado das Américas à teoria da evolução. São Paulo, Odysseus, 2002.

BOWLER, Peter J. Evolution. The history of an idea. Berkeley/Los Angeles/London, University of California Press, 1989. Cambridge, Cambridge University Press, 1996.

Charles Darwin. The man and his influence. Cambridge, Cambridge University Press, 1996.

CARMO, Viviane Arruda do. Concepções evolutivas de Charles Darwin no Origin of species e de Alfred Russel Wallace em Darwinism: um estudo comparativo. Dissertação de mestrado. São Paulo, PUC, 2006.

CASTAÑEDA, Luzia Aurelia. As idéias pré-mendelianas de herança e sua influência na teoria de evolução de Charles Darwin. Tese de doutorado. Campinas, IB-Unicamp, 1992.

DARWIN, Charles Robert. On the origin of species by means of natural selection or the preservation of favoured races in the struggle of life. London, Methuen, 1859.

[1872]. The origin of species by means of natural selection. $6^{\text {th }}$ edition. Chicago, Encyclopaedia Britannica, 1952 (Great Books of the Western World 49).

The variation of animals and plants under domestication. London, Murray, 1868. 2 vols.

Journal of researches into the geology and natural history of the countries visited during the voyage of the HMS Beagle [1845]. London, Routledge, 1891.

The autobiography of Charles Darwin. Nora Barlow (ed). New York, Harcourt Brace, 1958. 
Charles Darwin Diary of the voyage of HMS Beagle [1933]. Nora Barlow (ed.).

New York, Krause Reprints, 1969.

DESMOND, Adrian A.; MOORE, James R. A vida de um evolucionista atormentado. Trad. C. Azevedo. São Paulo, Geração Editorial, 1995.

GOULD, Stephen Jay. Ever since Darwin. New York, Norton, 1977.

JABLONKA, Eva; LAMB, Marion. "Soft inheritance: challenging the Modern Synthesis", in Genetics and Molecular Biology, 31. Ribeirão Preto, SBG, 2008, pp. 389-95.

LYELL, Charles. Principles of geology [1830-1833]. 3 vols. London, J. Cramer, 1970.

MARTINS, Lilian Al-Chueyr Pereira. "Alguns aspectos da teoria de evolução de August

Weismann", in José Luiz Goldfarb; Marcia Helena Ferraz (eds.). Anais. VII Seminário Nacional de História da Ciência e da Tecnologia. São Paulo, Editora da Unesp/Imprensa Oficial do Estado/Sociedade Brasileira de História da Ciência, 2000, pp. 279-83.

"August Weismann e evolução: os diferentes níveis de seleção", in Revista da

Sociedade Brasileira de História da Ciência [série 2] 1, n. 1. Rio de Janeiro, SBHC, 2003, pp. 53-74.

"Materials for the study of variation de William Bateson: um ataque ao

Darwinismo?", in Lilian Al-Chueyr Pereira Martins; Anna Carolina Krebs Pereira Regner;

Pablo Lorenzano (eds.). Ciências da vida: Estudos históricos e filosóficos. Campinas,

AFHIC, 2006, pp. 259-82.

"Herbert Spencer e o Neo-Lamarckismo: um estudo de caso", in Roberto de

A. Martins et al. (eds.). Filosofia e História da Ciência no Cone Sul. $3^{\circ}$ Encontro. Campinas, AFHIC, 2008, pp. 286-94.

MARTINS, Roberto de Andrade. "George John Romanes e a teoria da seleção fisiológica", in Episteme 11, n. 24, Porto Alegre, 2006, pp. 197-208.

MAYR, Ernst. The growth of biological thought. Diversity, evolution and inheritance.

Cambridge/MA, The Belknap Press, 1982.

POLIZELLO, Andreza. Modelos microscópicos de herança no século XIX: a teoria das estirpes de Francis Galton. Dissertação de mestrado. São Paulo, PUC, 2009.

REGNER, Anna Carolina Krebs Pereira. "A teoria darwiniana da seleção natural sem Malthus", in Roberto de A. Martins et al. (eds). Filosofia e História da Ciência no Cone Sul. $3^{\circ}$ Encontro. Campinas, AFHIC, 2008, pp. 48-64.

REIF, Wolf-Ernst; JUNKER, Thomas; Hoßfeld, Uwe. "The synthetic theory of evolution: general problems and the German contribution to the synthesis", in Theory Bioscience, n. 119, Springer, 2000, pp. 41-91.

SANTOS, Cintia Graziela. Da teoria sintética da evolução à síntese estendida: o papel da plasticidade fenotípica. Tese de doutorado. Ribeirão Preto, FFCLRP-USP, 2015.

SMOCOVITTIS, Vassiliki Betty. Unifying biology - The evolutionary synthesis and evolutionary biology. Princeton, Princeton University Press, 1996.

WALLACE, Alfred Russel. Darwinism. An exposition of the theory of natural selection with some of its applications. 2nd edition. London, Macmillan and Co., 1890.

WEISMANN, August. The evolution theory. 2 vols. Trad. J. A. Thomson e M. R. Thomson. London, Edward Arnold, 1904.

YOUNG, D. The discovery of evolution. Cambridge, Cambridge University Press, 1992. 